\title{
Prevalence of Hypertension in Women Working in Different Educational Institutes of District Mianwali, Punjab, Pakistan
}

\author{
Syed Sikandar Habib ${ }^{1 *}$, Saira $\mathrm{Naz}^{2}$, Anum Sadeeq ${ }^{1}$, Muhammad Zohaib Iqbal ${ }^{1}$, Maryam Ali ${ }^{1}$, Rizwan Hanif ${ }^{1}$, \\ Muhammad Asif Malik ${ }^{1}$, Nadia Khan ${ }^{1}$, Hansa Gul ${ }^{1}$ and Asma Mushtaq ${ }^{2}$ \\ ${ }^{1}$ Department of Biological Sciences, University of Sargodha Sub Campus Mianwali Punjab, Pakistan \\ ${ }^{2}$ Department of Zoology, University of Lahore Sub Campus Sargodha, Pakistan
}

Submission: May 01, 2019; Published: June 13, 2019

*Corresponding author: Syed Sikandar Habib, Department of Biological Sciences, University of Sargodha Sub Campus Mianwali Punjab, Pakistan

\begin{abstract}
The present study was carried out to checked the elevation of hypertension level and risk factors associated with hypertension in the different educational sectors of Mainwali district. The questionnaire was design to obtained the data, which comprises of three parts i.e. part one comprises of demographic records (Age, weight etc), second were related to life style character (obesity, physical inactivity etc) and third one consist of the elements in blood like calcium, sodium, potassium, ferritin level and HB\%. Basic descriptive statistical analysis, Chi - square test and odd square estimation was used to analyse the data. The result showed that the demographic characters are main cause of hypertension. Increasing age (above 40 year), weight (above 63) and body mass index cause elevation of blood pressure. Low level of education and post increase the blood pressure. Urban areas (65\%) had higher rate of hypertension. Obese women (67\%), physical activity have low prevalence of hypertension $(75 \%$ in normotensive and $18.35 \%$ in hypertensive. Low socioeconomic status also causes prevalence of hypertension. High level of sodium (136.84 mEq/L), calcium $(2.22 \mathrm{mg} / \mathrm{dL})$ and potassium $(4.15 \mathrm{mEq} / \mathrm{L})$ increases the higher risk of hypertension. Mean value of HB level is higher in normotensive $(11.40 \mathrm{~g} / \mathrm{dl})$ and pre-hypertensive $(11.15 \mathrm{~g} / \mathrm{dl})$ individual. Ferritin level was high in normotensive group (118.77ng/ $\mathrm{ml}$ ) but low in pre-hypertensive (115.74ng/dl) and hypertensive group (114.33ng/dl). The low concentration of HB and ferritin affect the blood pressure and causes prevalence of hypertension. The present study provided data about factors that elevate the blood pressure and caution that will minimize our blood pressure.
\end{abstract}

Keywords: Hypertension; Elevated; Normotensive; Pre-hypertensive; Body mass index and Blood

Abbreviations: WHO: World Health Organization; BMI: Body Mass Index; SES: Socio-Economic Status

\section{Introduction}

Hypertension is the leading preventable risk factor for premature death and disability worldwide [1]. In 2000 it is estimated that $26.4 \%$ of the global adult population, or 972 million people, had hypertension and is expected to rise to 1.56 billion in 2025 [2]. It is responsible for about $6 \%$ (9 million) of deaths worldwide [3]. Hypertension is enormously affecting the working groups. The World Health Organization (WHO) estimated that there were over 20 million cardiovascular deaths in 2015, which was account for $30 \%$ of deaths worldwide [4]. Hypertension is a common chronic medical condition affecting people in Pakistan and the rest of the world [5]. Hypertension is considered to be one of the major health issue due to its increasing frequency [6]. The reason for uncontrolled hypertension in Pakistan is high due to lack of awareness, knowledge, adherence, and attitudes of Pakistani patients with hypertension [7]. In Pakistan $50 \%$ people with hypertension were diagnosed and only half of these were ever treated [8].
High blood pressure is a major risk factor for strokes, heart failure, chronic kidney disease, coronary artery disease and cognitive decline that is ultimately responsible for causing over $60 \%$ of deaths in developed countries and $80 \%$ in developing countries, including Pakistan [9]. Income, education, and occupation are the most commonly used indicators or measures of the socioeconomic status of an individual. Although its measurement is difficult in the developing countries, household income has shown consistent association to the general measures of health [10]. Educational status is also widely used as a measure of socioeconomic status and is related to many health outcomes [11].

The results from many middle income countries are also showing positive association between socioeconomic status and hypertension [12]. All over world one billion people suffer from hypertension. For example its prevalence rate in rural India is $3.4 \%$, China and Korea is $25-30 \%$ and in USA it is $18-22 \%$ [13]. In Pakistan prevalence of hypertension has increased from 
$17 \%$ to $35 \%$ in 1980 to 2008 [14]. The present study intends in understanding the level of hypertension and factors that affect the educational authority and cause of such disease in district Mianwali. In addition to check out the effect of demographic and lifestyle related factors such as age, education, weight, socioeconomic status etc. on prevalence of hypertension.

\section{Materials and Methods}

\section{Study area specifications}

Mianwali district in Pakistan is the border district between two provinces (Punjab and Khyber Pakhtunkhwa). According to 2017 Census the total population of Mianwali district was 1546094. As per Census 2017 the city includes $21.2 \%$ people live in rural areas and $78.8 \%$ people live in urban areas.

\section{Data collection}

Data collection was completed during the period of September 2018 to February 2019. The data was collected in different schools and colleges during working duration. Questionnaires were designed for the study. The sample for this study consisted of 400 subjects who had answered all the questions. Patients like diabetic, heart patients or any other affected person was included in study.

\section{Inclusion criteria}

Female who were working in educational institutes and answered all the questions were included in this study. Patients like diabetic, heart patients or any other affected person was also included in this study.

\section{Exclusion criteria}

Participant who did not provided all values for the variables were not included in present study. In educational institute class 4 , education officers and other checking officers were excluded.

\section{Study layout and setting}

Two study sites, government schools and colleges, was purposefully selected based on their work force stability. Then private school and colleges was selected for collecting the data. The sample population included 400 women subjects (aged 20-60 years) who had answered all the questions respectively. Participant who did not provide all values for the variables were not included in present study. The information included demographic characteristics (age, sex, body weight, height, education, history of hypertension, cigarette smoking, alcohol consumption and administration of anti-hypertensive medications), life style characteristics and detection of transition element in blood. The subjects were divided in three groups as normotensive, pre-hypertensive and hypertensive. Three blood pressure ranges as shown below;

i. Normotensive with systolic blood pressure is 120 $\mathrm{mmHg}$ or lower than $120 \mathrm{mmHg}$ and diastolic blood pressure is $80 \mathrm{mmHg}$ or lower than $80 \mathrm{mmHg}$. ii. Pre-hypertensive with systolic blood pressure between 121-139 mmHg or diastolic blood pressure between 81-89 $\mathrm{mmHg}$.

iii. Hypertensive with systolic blood pressure more than $140 \mathrm{mmHg}$ or diastolic blood pressure more than $90 \mathrm{mmHg}$.

\section{Questionnaires design}

It comprises of three parts i.e.

a) Part one - comprises of demographic records including age, height, weight, body mass index, occupation, health goal, level of education, post, married or unmarried, rural or urban, veg or non-veg.

b) Part two - were related to life style character like obesity, physical inactivity, tobacco smoke, socioeconomic status, stress, alcohol drinking, unhealthy diet.

c) Part three - consist of the elements in blood like calcium, sodium, potassium, ferritin level and HB\%.

\section{Research variables}

Age: Age is considered the vital variable and is determined from the date of birth mentioned in national identity card.

- Group 1: Age limits 20-30 year

- Group 2: Age limits 30-40 year

- Group 3: Above 40 year

Body mass index: For all subject weight in $\mathrm{Kg}$ and height in meter was recorded. Height was measured to the nearest $0.5 \mathrm{~cm}$, without shoes and eyes looking straight. Weight was measured to nearest 100 grams without shoes. Body mass index (BMI) was calculated as weight $(\mathrm{kg}) /$ height $(\mathrm{m}) 2$. Overweight and obesity was defined as body mass index is equal to or greater than thirty, according to the World Health Organization (WHO) criteria 19.

Information about life style and habits: The data about life style and habits was collected through questionnaire from each individual. Information about health history, family history of hypertension, physical activity and health goal was asked in questionnaire.

Monthly income: Economic status of any person has very direct impact on his/her mental health and so effect the blood pressure. Three groups were made based on monthly income are;

- Group 1: Having monthly income less than 15000

- Group 2: Having monthly income between 1500050000

- $\quad$ Group 3: Having monthly income greater than 50000

Residential background: Residential background was considered as; 
- $\quad$ Rural

- Urban

Family setup: Family setup was classified into two groups;

- $\quad$ Single family

- Joint family

Stressful event: Any stressful event has a very negative impact on B.P and can be classified into two groups.

- Yes

- $\quad$ NO

Educational status: In this study focus was been given to educational institutes and also to record the educational level of teachers. It was classified in three groups;

- Group 1: Graduated

- $\quad$ Group 2: Post graduated

- Group 3: MPhil researcher

Cardiovascular diseases: Due to high blood pressure stroke and heart failure occur throughout the world. The cardiovascular diseases were classified into two groups;

- $\quad$ Group 1: Yes

- $\quad$ Group 2: No

Marital status: Marital status was also classified into two groups;

- Group 1: Married

- Group 2: Unmarried

Detection of blood sugar: Sugar level was estimated by using digital glucometer. Prick the finger with small needle called lancet and put a drop of blood on test strip. Then put the strip into meter that show blood sugar level .we get result less than 15 seconds. If random sugar level exceeded from $180 \mathrm{mg} / \mathrm{dL}$ the

Table 1: Sampling sites for blood pressure measurement.

\begin{tabular}{|c|c|c|c|}
\hline Sr. No & Sampling sites & No of sites & Areas \\
\hline 1 & Government. Schools & 20 & Primary, Elementary and high school \\
\hline 2 & Private schools & 8 & Primary, Elementary and high school \\
\hline 3 & Government. colleges Mianwali & 1 & Government. Degree college \\
\hline 4 & Private colleges & 4 & Punjab, Superior, Alnoor and Alsuffah colleges \\
\hline
\end{tabular}

\section{Screening of sampling sites with respect to blood pressure}

Table 2: Screening of sampling sites with respect to blood pressure.

\begin{tabular}{|c|c|c|c|c|}
\hline Sampling point types & Number of sites & Minimum BP & Maximum BP & Mean Std. deviation \\
\hline Government. School & 14 & $95 / 70=1.35$ & $185 / 105=1.80$ & $1.5750 \pm 0.22$ \\
\hline Private School & 4 & $110 / 70=1.60$ & $150 / 95=1.60$ & $1.6000 \pm 0.00$ \\
\hline Government. College & 2 & $100 / 70=1.42$ & $170 / 100=1.70$ & $1.5600 \pm 0.16$ \\
\hline Private college & 2 & $110 / 70=1.60$ & $170 / 90=1.90$ & $1.7500 \pm 0.17$ \\
\hline
\end{tabular}

person was considered as diabetic [15]. These were also classified as;

- $\quad$ Group 1: Diabetic

- $\quad$ Group 2: Non diabetic

Detection of elements in blood: One milliliter blood was taken from each individual for detection of elements. The blood was collected in plain tube for separation of serum and plasma. Serum was separated by centrifugation and then by this serum Na level, Ca level, K level and ferritin level was detected. $\mathrm{Hb} \%$ was noted by direct blood sample in PAF (Pakistan air force) hospital blood bank. For elements detection Manual test and electrolyte analyzer test were used.

Blood pressure measurement: Blood pressure in the right arm was measured. Systolic and Diastolic blood pressure were taken as mean of three readings. First blood pressure measurement was taken in the beginning of interview; second reading was noted during interview. A third blood pressure reading was noted after interview. The mean of all three readings were used to define BP for analysis.

\section{Statistical analysis}

Data were analyzed and studied through the statistical package for social science (SPSS, version 21). Basic descriptive statistics data analysis, Chi - square test was applied on variables. This test was used to determine the significant relationship among demographic factors. Odd ratio estimation and association test was applied that shows the high chance of hypertension between two sites.

Results

\section{Sampling sites}

Table 1 shows the educational institutes of district Mianwali. Thirty-three sites from the Mianwali were visited. In Government Schools and colleges deviation was found in blood pressure as compared to the Private schools and colleges. 
A great inconsistency was found in blood pressure level. The high blood pressure level was found in government sector with respect to their age as shown in the Table 2.

\section{Selection of sample for different exposure groups}

A total of 352 samples were collected from the entire site. The selected samples were 285 in which prevalence of diabetes was recorded; $8 \%$ in normotensive, $12 \%$ in pre-hypertensive and $22 \%$ in hypertensive. The record of other diseases like headTable 3: Selection of sample for different exposure groups.

\begin{tabular}{|c|c|c|c|c|}
\hline Categories & Normotensive $(\mathrm{N}=120)$ & Pre-hypertensive $(\mathrm{N}=90)$ & Hypertensive $(\mathrm{N}=142)$ & Total $(\mathrm{N}=352)$ \\
\hline Selected & $100(83 \%)$ & $65(72 \%)$ & $120(84 \%)$ & $285(81 \%)$ \\
\hline Diabetes & $8(8 \%)$ & $8(12 \%)$ & $22(18 \%)$ & $38(13 \%)$ \\
\hline Headache & $46(46 \%)$ & $50(73 \%)$ & $72(60 \%)$ & $168(59 \%)$ \\
\hline Cardiovascular disease & $4(4 \%)$ & $1(1 \%)$ & $14(12 \%)$ & $19(7 \%)$ \\
\hline Other diseases & $41(41 \%)$ & $6(9 \%)$ & $12(10 \%)$ & $59(20 \%)$ \\
\hline
\end{tabular}

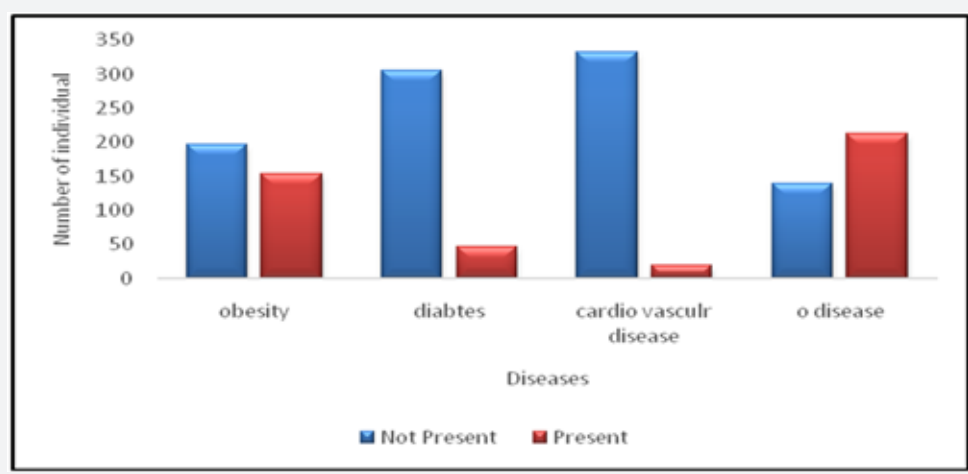

Figure 1: level of obesity, diabetes, cardiovascular diseases and other diseases.

\section{Demographical characteristics of selected sample}

Table 4: Demographical characteristics of selected samples.

\begin{tabular}{|c|c|c|c|}
\hline Characteristics & Normotensive (120) & Pre-hypertensive (90) & Hypertensive (142) \\
\hline Age (year) & $1.33 \pm 0.51$ & $1.51 \pm 0.58$ & $2.13 \pm 0.72$ \\
\hline Weight (Kg) & $57.19 \pm 9.50$ & $62.79 \pm 8.62$ & $63.44 \pm 10.45$ \\
\hline Height(m) & $1.59 \pm 0.06$ & $1.58 \pm 0.07$ & $1.6 \pm 0.07$ \\
\hline Gov school N (\%) & $58(48.33)$ & $37(41.11)$ & $105(44.4)$ \\
\hline Gov colleges N (\%) & $6(5)$ & $6(6.7)$ & $5(3.5)$ \\
\hline Private schools N (\%) & $48(40)$ & $40(44.4)$ & $24(17.2)$ \\
\hline Private colleges N (\%) & $8(6.7)$ & $7(7.77)$ & $7(4.96)$ \\
\hline
\end{tabular}

Demographical characteristics such as age, weight, height and body mass index were different in all three categories. The mean value and standard deviation for age, weight, height and body mass index was higher in hypertensive individual than pre-hypertensive and to the normotensive individuals (Table 4). On the basis of blood pressure different sites indicated that out of 120 normotensive participants $48.33 \%$ were from government schools, 5\% from government colleges, $40 \%$ from private schools and $6.6 \%$ were from private colleges. In pre-hypertensive, results were different. Out of 90, 41.1\% were from government schools, $6.67 \%$ were from government colleges, ache, body pain, legs pain, blurry vision etc. was $46 \%$ in normotensive, $50 \%$ pre-hypertensive and $72 \%$ in hypertensive. Cardiovascular diseases were observed more common in hypertensive due to high blood pressure. Its percentage in normotensive was recorded as $4 \%$, in pre-hypertensive $1 \%$ and in hypertensive $12 \%$ and the record of other diseases percentage were $41 \%$ in normotensive, $9 \%$ pre-hypertensive and $10 \%$ hypertensive (Table 3 \& Figure 1). 


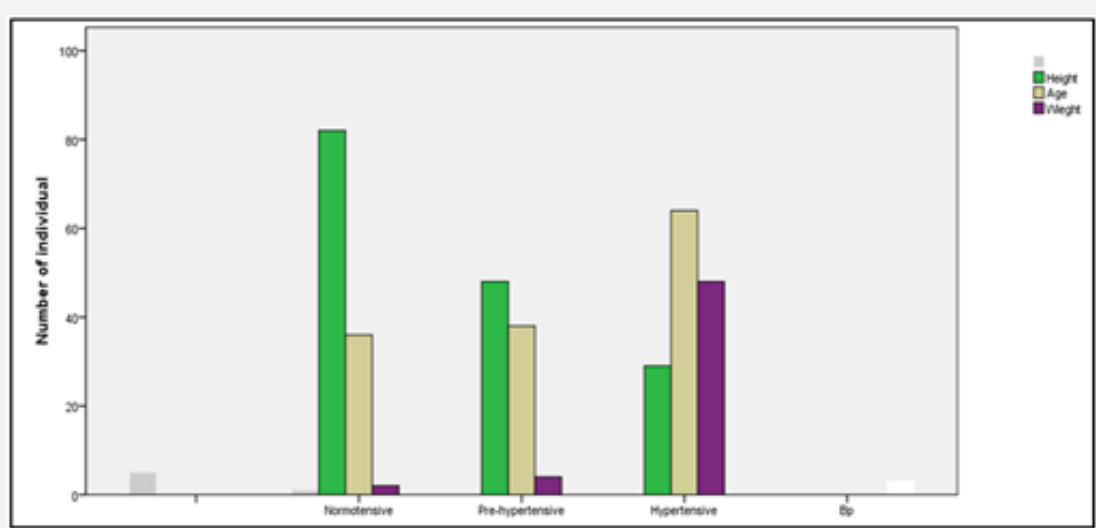

Figure 2: Represent the mean of Age, Weight and Height in Normotensive, Pre-hypertensive and Hypertensive.

\section{Odd ratio estimation and association tests}

Table 5: Odd ratio (OR) estimation and association test for prehypertension in different site.

\begin{tabular}{|c|c|c|c|c|}
\hline Groups & Pre-hypertensive (90) & Normotensive (120) & OR & Peferences \\
\hline Govt. schools & 37 & 58 & $0.89(0.26-3.02)$ & \multirow{2}{*}{$0.001(193.4)$} \\
\hline Govt. colleges & 5 & 7 & $0.81(0.24-2.78)$ & \\
\hline Private schools & 41 & 47 & $0.99(0.33-2.98)$ & \\
\hline Private colleges & 7 & 8 & \\
\hline
\end{tabular}

Estimation and association test for prehypertension and hypertension was conducted in different sites. Chi square test shows the relation between different selected sites with prehypertension and hypertension (Table 5).

The results of odd ratio estimation showed that the chances of hypertension was higher in private schools (2.39) as compared to the government colleges (1.17), but it was observed low in private colleges also (0.68) (Table 6).

Table 6: Results for odds ratio (OR) estimation and association test for Hypertension in different sites.

\begin{tabular}{|c|c|c|c|c|}
\hline Group & Hypertensive $(\mathrm{N}=142)$ & Normotensive (120) & OR & P $^{2}$ \\
\hline Govt. school & 97 & 58 & References & \multirow{2}{*}{$0.00(263.4)$} \\
\hline Govt. colleges & 10 & 7 & $1.17(0.42-3.24)$ & \\
\hline Private schools & 28 & 47 & $2.39(0.82-7.01)$ & \\
\hline Private colleges & 7 & 8 & $0.68(0.23-2.08)$ & \\
\hline
\end{tabular}

Table 7: Results for odd ratio (OR) estimation and association test for prehypertension in different sites (adjusted for age).

\begin{tabular}{|c|c|c|c|c|}
\hline Groups & Pre-hypertensive (N=90) & Normotensive $(\mathrm{N}=120)$ & OR & \multirow{2}{*}{ P $\mathbf{x}^{2}$} \\
\cline { 1 - 4 } $20-30$ & 47 & 82 & References & \multirow{2}{*}{$0.02(7.37)$} \\
\hline $30-40$ & 37 & 36 & $0.58(0.31-0.98)$ & $0.34(0.06-1.81)$ \\
\hline
\end{tabular}

For prehypertension and hypertension odd ratio estimation and association test was adjusted for age. (Table 7). Adjustment of data involved selection of sample with different age groups. It

was noted that odd ratio for pre-hypertensive age 30-40 is greater (0.58) than age 40 and above (0.34).

Table 8: Results for odd ratio (OR) estimation and association test for hypertension in different sites (Adjusted for age).

\begin{tabular}{|c|c|c|c|c|}
\hline Groups & Hypertensive (N=142) & Normotensive (120) & OR & \multirow{2}{*}{${\text { P } \mathbf{x}^{2}}^{*}$} \\
\hline $20-30$ & 28 & 82 & References & $0.000(77.87)$ \\
\hline $30-40$ & 63 & 36 & $0.19(0.10-0.35)$ & \\
\hline 40 Above & 51 & 2 & $0.06(0.01-0.29)$ & \\
\hline
\end{tabular}

The results for hypertensive and normotensive in case of aged group (above 40 ) odd ratio is lower (0.06) other 30-40 group (0.19) (Table 8).

\section{Elements}

Different experiments were involved for the detection of elements in blood with relation to different diseases [16]. In this 
study three minerals ( $\mathrm{Na}, \mathrm{K}$ and $\mathrm{Ca}$ ) and two proteins hemoglobin and ferritin level were analyzed to understand the effect of blood pressure.

Normally the sodium level in blood ranges from 135 to 145 $\mathrm{ml}$ equivalents per liter $(\mathrm{mEq} / \mathrm{l})$. Higher concentration of sodium is caused by diabetes insipidus, fluid loss or eating too much salt or sodium bicarbonate. Too much sodium intake can lead to too much body fluid retention which elevates the blood pressure [17]. Low level of sodium can be caused due to high water level in the body and hormone problems [18].

The normal potassium level in blood is 3.5-5.0 mille Equiv- alents per liter ( $\mathrm{mEq} / \mathrm{l})$. If the level is from 5.1 to $6.0 \mathrm{mEq} / \mathrm{l}$, it is considers as mild hyperkalemia and if it is in from 6.1 to 7.0 $\mathrm{mEq} / \mathrm{l}$ it is known as moderate hyperkalemia. The level above 7 $\mathrm{mEq} / \mathrm{l}$ is called as sever hyperkalemia [16]. The Calcium levels alter with age. A normal teenager has calcium levels in between 10.0 and $10.7 \mathrm{mg} / \mathrm{dl}$. Normal ferritin level ranges from 12 to 300 $\mathrm{ng} / \mathrm{ml}$ (nano grams per milliliter) of blood in male and 12 to 150 $\mathrm{ng} / \mathrm{ml}$ in female. The hemoglobin level is expressed as amount of hemoglobin in $\mathrm{g} / \mathrm{dl}$ (grams per deciliter) of blood. The normal range of HB depends on age and gender of a person. Adult women have 12 to $16 \mathrm{~g} / \mathrm{dl}$.

\section{Comparison of means of blood metal levels among different blood pressure groups}

Table 9: Comparison of means of blood metal levels among different blood pressure groups.

\begin{tabular}{|c|c|c|c|}
\hline Elements Molar Mass & Normotensive (N=120) & Pre-hypertensive (N=90) & $11.15 \pm 2.13$ \\
\hline HB $\%$ & $11.40 \pm 1.94$ & $115.74 \pm 31.79$ & $11.06 \pm 2.38$ \\
\hline Ferritin level & $118.77 \pm 31.24$ & $134.54 \pm 7.57$ & $136.84 \pm 8.22$ \\
\hline $\mathrm{Na} / 23$ & $133.34 \pm 2.76$ & $4.15 \pm 0.15$ & $4.15 \pm 0.15$ \\
\hline $\mathrm{K} / 39$ & $4.17 \pm 0.14$ & $2.23 \pm 0.15$ & $2.22 \pm 0.23$ \\
\hline $\mathrm{Ca} / 40$ & $2.29 \pm 0.45$ & & \\
\hline
\end{tabular}

Table 9 shows the comparison of means of blood metal-level among different blood pressure groups. It indicated comparison of $\mathrm{HB} \%$, Ferritin level, $\mathrm{Na}, \mathrm{K}$ and $\mathrm{Ca}$. All groups had small variation in the level of $\mathrm{HB} \%$, ferritin level, $\mathrm{Na}, \mathrm{K}, \mathrm{Ca}$. HB level was higher in normotensive individual as compared to the pre-hypertensive and hypertensive. Ferritin level was also higher in normotensive participants when it was compared with hypertensive and pre-hypertensive. The mean of Na was comparatively higher in pre-hypertensive individuals. $\mathrm{K}$ and Ca level shows small variation in all groups. This variation shows a small difference in points. Concentration of $\mathrm{K}$ was a little bit higher as compared to the pre-hypertensive and hypertensive. Ca shows same level in all of three groups. For HB\% and ferritin increasing order of levels in different groups was normotensive > pre-hypertensive $>$ hypertensive. For Na increasing order of level was pre-hypertensive $>$ normotensive $>$ hypertensive. For Ca and $\mathrm{K}$ there was no increasing order of level in groups, all groups having almost equal values.

Figure 3 represents the level of $\mathrm{Na}, \mathrm{K}, \mathrm{Ca}, \mathrm{Hb}$ and ferritin level in Normotensive, Pre-hypertensive and hypertensive groups. $\mathrm{Na}$ level was higher in pre-hypertensive group and its concentration was lower in hypertensive and Normotensive population. Ferrtin level was higher in Normotensive individuals. $\mathrm{Hb}, \mathrm{K}$ and Ca had small variation in all groups.

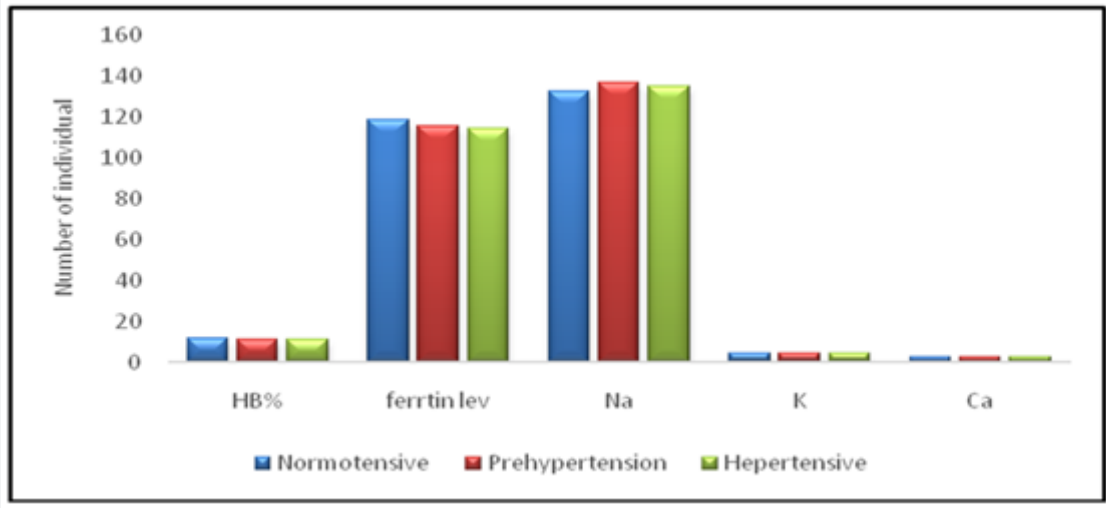

Figure 3: Level of HB, Ferritin, Sodium, Potassium and Calcium in Normotensive, Prehypertensive and hypertensive.

Current study revealed close association of Hypertension with different diseases. It was observed that the women affected by diabetes and headache were more likely to have high blood pressure as compared to non-affected women. About $98 \%$ hypertensive women had headache. Similar observations were re- ported in the study of Bender et al. [19]; Zampaglione et al. [20]. This study was in the agreement of previous study conducted by Cress \& Nieto [21]. Their findings revealed that development of type 2 diabetes was 2.5 times greater in hypertensive person than in normotensive group. In our findings, cardiovascular dis- 
ease was common in hypertensive groups as compared to normotensive and Pre-hypertensive. These observations were in accordance of previous study conducted in East Asian population by Saleem et al. [7].

In the present study, the association of high blood pressure with age was examined. In this study it was shown that more aged individual (Above 40 years) have high prevalence of hypertension in both sectors (Govt, Private). During study, it was observed that in private institute individuals, in spite of being young age, have high blood pressure due to over burden of work. This study was in the agreement of previous study conducted in United State by Hajjar \& Kotchen [22].

It was observed in the present study that obesity is directly related to high blood pressure. As $67 \%$ obesity was found in hypertensive group. These findings were in accordance with the study conducted by Flegal et al. [23]. They observed that obesity is directly related to hypertension because obese women had, accumulated high fats (visceral fats) in their body and having higher risk of Hypertension.

In present study it was observed that no female was found as a smoker. This study was not in agreement with previous studies conducted in Isfahan by Meraci et al. [24].

The findings of present study suggested that women living in urban areas were at higher risk of hypertension as compared to women of rural areas. This may be due to noise exposure, life style, and change in habit, different diseases and obesity. This study was the confirmation of previous research conducted in India by Gupta [25].

It has been observed in the current study that socio-economic status (SES) has close association with hypertension. This may be due to over burden of work, low income and low educational status in private sectors. In government sectors mostly aged women have high blood pressure but their economic status does not affect their BP. The observations in government sectors are not in agreement with previous studies. But in private institute these observations was in accordance with the study conducted by Chandola et al. [26].

Results of present study revealed the association between prevalence of hypertension and stress. Our finding indicated that mostly hypertensive women have stressful events that cause negative effects on their blood pressure. Similar results were also found by Singh [27].

In current study the association of healthy diet with hypertension prevalence was examined. Maximum numbers of samples in this study were non vegetarian. They intake a diet that consist of too much salts, calories and sugar that leads to higher risk of hypertension. These observations were found in urban population. A number of samples were used vegetables and animal resources that reduce their blood pressure. This study was in the agreement of previous study of Schmidlin et al. [28].
Our study indicated that body mass index has significant relationship with hypertension. It was observed that mostly female have greater than $25 \mathrm{~kg} \mathrm{~m}-2$ body mass index. These women were over weighted or obese. This study was in the agreement of previous study conducted in Arabain Peninsula Channanath et al. [29].

The current study suggested that Ferritin level was high in normotensive case as compared to Pre-hypertensive and hypertensive individual. Our findings indicated that reduction in Ferritin level leads to high blood pressure. These findings were in accordance with the study conducted by Jehn et al. [30]; Fumeron et al. [31].

A study conducted in China by Chen [32]. Their findings illustrated that reduce intake of dietary sodium lower the blood pressure. Higher level of $\mathrm{Na}$ increases the risk of hypertension, also proved an association between dietary $\mathrm{Na}$ and blood. This study was in the agreement of previous study that sodium level had substantial association with hypertension pressure conducted by Jaitovich \& Bertorello [33]; Seeliger et al. [34], Park et al. [35].

It was observed in the present study that calcium has no significance correlation with hypertension. Our observations indicated that increasing or decreasing concentration of $\mathrm{Ca}$ has no effect on the blood pressure. The study was in confirmation of previous research conducted by Kosch et al. [36].

The findings of present study suggested that there was no association between Potassium and hypertension. These findings were in accordance with the Hajjar et al. [37], in US population. They concluded that dietary potassium intake was negatively associated to blood pressure.

\section{Conclusion}

The findings of present study revealed that various factors have close association with hypertension. Age and weight were directly related with prevalence of hypertension. Prevalence of hypertension was also observed in obese and aged women, having cardiovascular diseases, low physical activity, low nutritional status, low socioeconomic status, and low income. The urban people have high hypertension prevalence due to life style changes and habits. The increasing level of sodium, calcium and potassium increases the prevalence of hypertension. The high level of $\mathrm{Hb}$ and ferritin was observed in normotensive group. Their low concentration causes the hypertension prevalence.

\section{References}

1. Kearney PM, Whelton M, Reynolds K, Whelton PK, He J (2004) Worldwide prevalence of hypertension: a systematic review. J Hypertens 22(1): 11-19.

2. Bromfield S, Muntner P (2013) High blood pressure: the leading global burden of disease risk factor and the need for worldwide prevention programs. Curr Hypertens Rep 15(3): 134-136.

3. World Health Organization (WHO) (2014) Joint Water Supply and San- 
itation Monitoring Program. Progress on drinking water and sanitation, Geneva, Switzerland.

4. Dochi M, Sakata K, Oishi M, Tanaka K, Kobayashi E, et al. (2009) Smoking as an independent risk factor for hypertension: a 14-year longitudinal study in male Japanese workers. Tohoku J Exp Med 217(1): 37-43.

5. Aziz KU, Faruqui AM, Teri M, Davis CE, Abenathy J (2005) Blood pressure and hypertension distribution in a lower middle class urban community in Pakistan. J Pak Med Assoc 55(8): 333-338.

6. Mohan S, Campbell NR (2009) Hypertension management: time to shift gears and scale up national efforts. Hypertension 53(3): 450-451.

7. Saleem F, Hassali MA, Shafie AA, Atif M (2012) Drug attitude and adherence: a qualitative insight of patients with hypertension. J Young Pharm 4(2): 101.

8. Sailesh M, Norm RCC (2009) Hypertension management: time to shift gears and scale up national efforts. Current Hypertension Report 53(3): 450-451.

9. World Health Organization (WHO) (2013) A global brief on hypertension: silent killer, global public health crisis. Geneva, Switzerland.

10. Kanjilal S, Gregg EW, Cheng YJ, Zhang P, Nelson DE, et al. (2006) Socioeconomic status and trends in disparities in 4 major risk factors for cardiovascular disease among US adults, 1971-2002. Arch Intern Med 166(21): 2348-2355.

11. Fotso JC, Defo B (2005) Measuring socioeconomic status in health research in developing countries: should we be focusing on households, communities or both?. Social Indicators Research 72(2): 189-237.

12. Gilberts EC, Arnold MJ, Grobbee DE (1994) Hypertension and determinants of blood pressure with special reference to socioeconomic status in a rural south Indian community. J Epidemiol Community Health 48(3): 258-261.

13. Erem C, Hacihasanoglu A, Kocak M, Deger O, Topbas M (2008) Prevalence of prehypertension and hypertension and associated risk factors among Turkish adults: Trabzon Hypertension Study. J Public Health (Oxf) 31(1): 47-58.

14. Danaei G, Finucane MM, Lin JK, Singh GM, Paciorek CJ, et al. (2011) National, regional and global trends in systolic blood pressure since 1980: systematic analysis of health examination surveys and epidemiological studies with 786 country-years and $5 \cdot 4$ million participants Lancet 377(9765): 568-577.

15. Alberto P, Trombini P, Gelosa M, Mauri V, Pecci V, et al. (2002) Increased serum ferritin is common in men with essential hypertension. J Hypertens 20(8): 1513-1518.

16. Resch M, Bergler T, Fredersdorf S, Griese DP, Weil J, et al. (2010) Hyperaldosteronism and altered expression of an SGK1-dependent sodium transporter in ZDF rats leads to salt dependence of blood pressure Hypertens Res 33(10): 1082-1088.

17. Muhsin SA, Mount DB (2016) Diagnosis and treatment of hypernatremia. Best Pract Res Clin Endocrinol Metab 30(2): 189-203.

18. William B Farquhar, DG Edward, Claudine T, Jurkovitz MD (2014) Dietary Sodium and Health and association with high blood pressure New England Journal of Metabolism 1(2): 1-39.

19. Bender RS, Fong WM, Heitz S, Bisognano DJ (2006) Characteristics and management of patients presenting to the emergency department with hypertensive urgency. J Clin Hypertens (Greenwich) 8(1): 12-18.

20. Zampaglione B, Pascale C, Marchisio M, Cavallo Perin P (1996) Hypertensive urgencies and emergencies: prevalence and clinical presentation. Hypertension 27(1): 144-147.
21. Cress TW, Nieto FJ (2000) Hypertension and antihypertensive therpyas risk factors for type 2 diabetes mellitus. Atherrosclerosis Risk in Colmuni ties. Study 1(23): 905-912.

22. Hajjar I, Kotchen TA (2004) Trends in prevalence, awareness, treatment, and control of hypertension in the United States. Journal of American Society of Hypertension 290(2): 199-206.

23. Flegal KM, Carroll MD, Kit BK, Ogden CL (2012) Prevalence of obesity and trends in the distribution of body mass index among US adults. Journal of the American College of Hypertension 307(5): 491-497.

24. Meraci M, Feizi A, Bagher NM (2012) Investigating the prevalence of high blood pressure, type 2 diabetes mellitus and related risk factors according to a large general study in Isfahan-using multivariate logistic regression model. British Journal of Hypertension 31(3): 145-147.

25. Gupta R (2004) Trends in hypertension epidemiology in India. J Hum Hypertens 18(2): 73-78.

26. Chandola T, Brunner E, Marmot M (2006) Chronic stress at work and the metabolic syndrome: prospective study. BMJ 332(7540): 521-525.

27. Singh AK (2010) The FDA's perspective on the risk for rapid rise in hemoglobin in treating CKD anemia: Quo Vadis Clin J Am Soc Nephrol 5(4): 553-556.

28. Schmidlin O, Sebastian AF, Morris RC Jr (2007) What initiates the pressor effect of salt in salt-sensitive humans? Observations in normotensive blacks. Hypertension 49(5): 1032-1039.

29. Channanath AM, Farran B, Behbehani K, Thanaraj TA (2015) Association between body mass index and onset of hypertension in men and women with and without diabetes: A cross-sectional study using national health data from the State of Kuwait in the Arabian Peninsula. BMJ Open 5(6): 7-43.

30. Jehn M. Clark JM, Guallar E (2004) Serum ferritin and risk of the metabolic syndrome in U.S. adults. Diabetes Care 27(2): 2422-2428.

31. Fumeron F, Péan F, Driss F, Balkau B, Tichet J, et al. (2006) Ferritin and transferrin are both predictive of the onset of hyperglycemia in men and women over 3 years: the data from an epidemiological study on the Insulin Resistance Syndrome study. Diabetes Care 29(9): 20902094.

32. Chen J (2010) Sodium sensitivity of blood pressure in Chinese populations. Curr Hypertens Rep 12(2): 127-134.

33. Jaitovich A, Bertorello AM (2010) Intracellular sodium sensing: SIK1 network, hormone action and high blood pressure. Biochim Biophys Acta 1802(12): 1140-1149.

34. Seeliger E, Lunenburg T, Ladwig M, Reinhardt HW (2010) Role of the renin-angiotensin-aldosterone system for control of arterial blood pressure following moderate deficit in total body sodium: Balance studies in freely moving dogs. Clin Exp Pharmacol Physiol 37(2): 4351.

35. Park J, Lee JS, Kim J (2010) Relationship between dietary sodium, potassium, and calcium, anthropometric indexes, and blood pressure in young and middle aged Korean adults. Nutr Res Pract 4(2): 155-162.

36. Kosch M, Hausberg M, Barenbrock M, Posadzy MA, Rahn KH, et al. (2011) Increased membranous calcium concentrations in primary hypertension: A causal link to pathogenesis?. J Hum Hypertens 15(2): 37-40.

37. Hajjar IM, Grim CE, George V, Kotchen TA (2001) Impact of diet on blood pressure and age-related changes in blood pressure in the US population. Arch Intern Med 161(4): 589-593. 
This work is licensed under Creative Commons Attribution 4.0 License

DOI: 10.19080/CTBEB.2019.19.556011

\section{Your next submission with Juniper Publishers} will reach you the below assets

- Quality Editorial service

- Swift Peer Review

- Reprints availability

- E-prints Service

- Manuscript Podcast for convenient understanding

- Global attainment for your research

- Manuscript accessibility in different formats ( Pdf, E-pub, Full Text, Audio)

- Unceasing customer service

Track the below URL for one-step submission https://juniperpublishers.com/online-submission.php 